NOTES

ON

\section{ACQUIRED LEPROSY}

\section{AS OBSERVED IN ENGLAND.}

By JONATHAN HUTCHINSON, F.R.C.S., LL.D., F.R.S.,

Consulting Surgeon to the Hospital for Diserses of the Skin, to the Royal London Ophthalmic Hospital, and to the London Hospital.

I.

AMONGS' the facts which are most likely to help us in the search for the cause of leprosy are the instances in which it originates in those who have left England and gone to reside in some place where the disease is endemic. In these cases we can usually put wholly aside any suspicion of inheritance, and in many instances we can ascertain the mode of life abroad and the class of possible influences to which they have been subjected with greater accuracy than in the case of natives. The problem is, in fact, in them a less complicated one, and their study is accordingly one of greater promise as regards definite results. I purpose to record on the present occasion some of the facts of this kind which have recently come under my observation, and in doing so shall keep carefully in view the question as to whether they throw any light upon the cause of the malady.

Before proceeding to make citation of cases, it may be well, however, to discuss a few general propositions. I do this with the greater pleasure because I believe it will be easy to show that there is far less of divergence in professional opinion on the matter and a far nearer approach to unanimity than is generally believed to be the case.

To take first the question of contagion, it is generally believed that the profession divides itself into two camps, one asserting contagion and the other denying it. Now the truth is probably nearly this. No one denies the possibility of contagion in what may be called the abstract or non-practical sense, while all, or very nearly all, doubt whether contagion takes any important share in the spread of the disease. A recent experiment by inoculation appears to have proved that contagion can be artificially effected, but it does not prove, and is very far from making probable, that accidental contagion is common or easy. With due care in the transplantation of a bit of living tissue, no doubt lupus might be transferred from one person to another and so also cancer, but neither of these diseases is contagious in a practical sense. In neither is there any necessity for isolation of the sufferer in order to give safety to others. Those who believe in the importance of the bacillus as being perhaps the vera causa of leprosy are bound also to believe that the disease may be contagious. The practical question is, however, under what conditions does it become so. On this point the testimony of modern observers in leprosy districts is very nearly unanimous. Neither in Norway, in Hindustan, or the West Indian Islands, do nurses or surgeons fear to come in contact with lepers from day to day for years together. So far as contagion is concerned, hundreds of surgeons, well acquainted with the dreadful nature of the disease, daily encounter the same risks that Father Damien did. They do so, however, in the firm conviction that the risk is nothing.

The sad illness and death of the hero-priest has impressed the public with the belief that the disease is contagious, whereas it proves no such thing. The risks to which he exposed himself were far other than those of contagion-they were those of food as well. When I visited the leper establishments in Norway some years ago, I made diligent inquiry for instances of apparent contagion; I asked more especially whether strangers visiting Norway ever contracted it. Everywhere I was met with an emphatic negative, but every where I was told of one well-known exception. This exception was a certain German officer who had come to live in Norway and had become a leper; but, added my informants, "he degraded himself and lived amongst the fishermen as they did, and he deserved to get it." The large leper establishments at Bergen and Molde were officered by healthy persons, and no one feared the disease. Recent microscopic discoveries have done something to explain the difficulty of contagion while at the same time confirming our belief in its possibility. They have shown that the microbe, which is no doubt the means of contagion, flourishes only in the true skin, and never invades the epidermis; and, further, that it is not present in the granulations of ulcerated parts. Thus it can probably be transferred only when special care is taken to secure the success of the experiment.

Our experience as to lepers in England is all in the strongest possible sense adverse to the belief in accidental contagion. We admit them into our hospitals, and observe no precautions; we allow them to mix freely with their relatives; in the case of children, to go to school; and, to give lastly the strongest possible proof, we permit leprous husbands to continue cohabitation with their unaffected wives, and no ill results ensue. I have within my present knowledge at least three murried couples living under the conditions suggested, and in no instance has the wife suffered. Indeed, to sum up, there has not been in England, within my knowledge, a single instance of even suspected contagion. I have never myself seen a single patient in whom the distase had not been acquired during residence abroad. The profession in general is agred as to these facts. and it is thus nearly unanimous as to the extreme rarity of contagion We admit its brr possibility, lut little more. On several other very impor:ant prints it may, I think, be said that, the profession is well informed and all but unanimous. We do not believe that there are any real varieties in leprosy. It is one and the same disease whenever it occurs and under whatever conditions it is produced. The diff-rent names which have been given are names only for different stages or for different manifestations in the same patient. The Norwegian fisherman, the Hindu peasant, the Sandwich islander, and the wealthy West Indian planter, all, if they become leprous, show the same symptoms. With slight differences in relation to vigour of constitution and exemption trom hardship, the disease runs the same course in all. This fact of sameness, without regard to social position of the sufferer, or to climate, is extremely important. It points us without fear of error to the inference that the cause must be always the same, and a very definite and peculiar one. There is no vagueness about the result, there can be no vagueness about the cause. A person is either a leper or he is not, he either has the poison and will of necessity experience ence its full and dire effects or he is wholly free.

Can we possibly doubt that the poison is a specific one-as specific, for instance, as those of syphilis, or of small-pox? Here, again, Hansen's discovery of the bacillus (confirmed as it has been on all hands) comes to our aid. It demonstrates to us the possible and probable cause of the specificity and sameness of the disease. We can understand wby it affects rich and poor alike, for the poison is one against which riches, and the social comforts which they bring, afford no protection whatever.

Not only is leprosy as we now know it the same in all parts of the world, but there is good reason to believe that it was always the same in times when its prevalence was far greater than it is now. Let us note in this connection that in countries where it has died out it has died out absolutely. Not a single sporadic case, for instance, is ever now seen in our own country. Every case that we see in British practice is an imported one coming from some country where the disease is still prevalent.

The facts to which reference has been made being generally admitted, and once for all considered as beyond debate, the problem before us in our search for a cause becomes I think much narrowed. We feel sure that this cause is not contagion, we feel sure that there is nothing in even the slightest degree associated with poverty, dirt, or hardship, we feel sure that nothing that we know of under the name of climate has anything to do with it. What then have we left us to inquire about? Little or nothing I would submit excepting the all-important question of food. Since it can begin without inheritance, is with the utmost difficulty contagious, since it affects those who live in hot climates, just as it does those who live in cold nnes, pays no respect to wealth and station, to age or sex, but of those who live in the districts and conform to the local modes of life picks out one here and another there, we are I think driven to the conclusion that it must depend upon some very special kind of poison of rare occurrence taken in connection with food. Such an hypothesis would cover all the facts, and none other would. I do not believe that it is possible to suggest any other that would not be instantly confuted by the facts. If we conceive that the bacillus is received into the body in some article of food, and add to our hypothesis that it is probably by no means commonly present, we see at once how the occasional but very rare infection of those who visit 
leprous districts may be brought about, and how it is that of the natives themselves only a minority suffer. We see also how it is that recoveries now and then occur in those who leave the dangerous districts, whilst they are seldom or never witnessed in those who remain.

If the hypothesis here explained be the correct one, the kind of investigation now required is evident. We know enough as to the clinical history of leprosy and as to its pathological anatomy. We accept the bacillus as, in some sense at least, its cause, and we now have to seek the spores of the bacillus in the foods employed in the districts in which it is prevalent. This will doubtless be a difficult and laborious matter, but by judicious collection of fucts I do not doubt that the scope of the inquiry may be narrowed to one of much srnaller compass. We have to find some kind of food which is used in all the districts in which the disease prevails, and which is either wholly or partially disused in those where it is not known. We have to ask in what directions the progress of European civilisation has modified the dietetic habits of the communities.

I will now proceed to cite such items of evidence as have come under my own observation, and to inquire how they bear upon th $;$ suggestions which I have ventured to make.

I will mention first the first case of leprosy which I ever saw, and one which has proved of extreme interest. It was that of a Jewish woman, who was under care at the Hospital for Diseases of the Skin in 1847, being at that time the subject of tubercular leprosy in a most severe form. Her age was 44 , and she had just returned from Jamaica, where she had resided for eleven years. She had been born in Portsmouth, and had lived in England until 32 years of age. During the greater part of her residence in Jamaica she had enjoyed excellent healtb. Her diet there was beef, turt $e$ and fish in great plenty, and vegetables in great variety. Her family was in comfortable circumstances, and she never suffered any kind of hardship. Allowing for some inaccuracy on her part as regards dates, we may believe that she suffir red from the disease for several years before leaving Jamaica, and that it remained in full force for several more after her return to England. She was under Dr. Addison's care in Guy's Hospital after ceasing to attend at Blackfriars, and subsequently she took a course of arsenic under Mr. Hunt's treatment. Whilst living in England her circumstances became, through a relative, much improved, and she took port wine freely. She thought that this was of great benefit to her, but whether this were so or not, it is an undoubted fact that the leprosy process in her gradually came to an end. I saw her in 1879, when she was 71 years of age, and she was then in excellent health, although much disfigured, somewhat crippled, and partially blind by what had happened in connection with her former disease.

This case proves, first, that leprosy may be acquired without inheritance, by residence in a district where it is endemic; secondly, that it is not necessary that there should be any exposure to hardship or poor food ; thirdly, and most importantly, that the leprosy processes may come entirely to an end during residence in England; fourthly, as regards the food hypothesis, we have the fact that the patient had eaten fish freely in Jamaica, almost every day, and that she abstained from it in England.

LIVERPOOL PORT.-Value of GoodAdministration at our Seaports : How Infectious Disease is Spread.-It is difficult to overestimate the value of the work done by a port sanitary authority, more especially in connection with the control of infectious diseases; and Dr. Stopford Taylor's annual report for 1888 gives a very good idea of what is, and what can be, done in this direction. Moreover, as an instance of what might occur were the precautions now in force to be diminished, he cites the case of a man who recently landed and went to a lodging-house, where he stayed for a few days. It was noticed that he had a few spots upon his face, but nothing was suspected. He then went to his friends in Anglesea, and several members of his family afterwards contracted small-pox. This disease was prevalent at several of the Spanish ports, and, as steamers make the passage within the period of incubation, several instances occurred in which some members of the (crews landed apparently well, and subsequently developed small-pox. Several cases were removed to the hospital on the arrival of the ships, and thus any possibility of the spread of infection was prevented. The number of emigrants leaving the port last year was larger than usual, but the sickness found among them was slight. Of thirty-seren patients remored to hospital, twenty-seven were suffering from measles,
THE CROONIAN LECTURES

ON THE RELATIONSHIP BETWEEN

\section{CHEMICAL STRUCTURE} AND

PHYSIOLOGICAL ACTION.

Delivered before the Royal College of Physicians of London.

BY T. LAUDER BRUNTON, M.D., D.Sc.EDIN., LL.D.ABER., F.R.S.

Fellow of the Royal College of Physicians; Assistant-Physician and Lecturer on Materia Medica at St. Bartholomew's Hospital.

LFCTURE III.

WE now pass from the prevention of disease to another subdivision of our subject. Antiseptics find their most important application in the prevention of disease. But many bodies belonging to this class have other actions which are extremely valuable in relation to the control and cure of disease. More especially is this true of their power to reduce temperature and relieve pain. We might therefore pass from antiseptics straight on to antipyretics. Or we might take another course, and on leaving antisepsis, one of the two greatest discoveries of modern therapeutics, we inight turn to the other, viz., anæsthesia, and proceed to the consideration of anæsthetics. Both plans have advantages of their own. If we take anæsthetics first, it allows us to a certain extent to follow the subject of the relation between chemical structure and physiological action historically, and it has the further advantage of allowing us to begin with bodies of simple chemical structure and to proceed from them to the more complex. Such an arrangement would undoubtedly be best in a textbook, but as my object here is not to give you a full account of all that is known in relation to the connection between chemical structure and physiological action, but rather to point out its relations to the treatment and cure of disease, I shall take the other method and pass from antiseptics directly to antipyretics. There is a natural link between those two classes of remedies. Not only are antiseptic and antipyretic properties generally possessed by the same substances, but we use the same remedies to destroy microbes both outside and inside the body, and also to reduce the fever which the microbes cause after their entrance into the organism.

Besides this, a number of new facts have been ascertained regarding the functions of protoplasm by the use of bodies belonging to the aromatic series. I wish particularly to call your attention to those facts because they may help us to explain the action of other classes of drugs as well as that of antipyretice.

Movements of Cells.

On observing isolated cells, such as the leucocytes of the blood, we can see that they are endowed with life, and will continue to move about on the stage of the microscope as independent organisms for a considerable time after the death of the animal from which they have been taken. Their movements are of two kinds, viz., one of simple contraction or extension of the protoplasm in various directions, while the cell remains in its place, and secondly. movements from place to place. I call your attention specially to those kinds of movement because both are probably of practical importance. The movements from place to place enable the leucocytes, as was first observed by Addison and then by Waller, to move out of the blood-vessels. The importance of this diapedesis and of the further movements of the leucocyte amongst the cells of the tissues has been clearly demonstrated by Cohnheim; and his followers; but it seems probable that movement of the protoplasm in a cell while it remains in situ may be no less important.

Respiratron in Cello.

Kühne showed that isolated cells have the power of absorbing oxygen, by placing them under the microscope in water containing a little oxy-hæmoglobin. After a while they absorbed the oxygen from the hæmoglobin and reduced it. This reduction was discovered by looking at the solution with the microspectroscope. and noticing that it gave the band of reduced hæmoglobin instead of oxy-hæmoglobin as at first. The experiments of Ludwig an his scholars upon circulation through single organs or parts of the body isolated :from the rest, and also those of Pfluger and his school upon the gases of the blood, have shown that oxidation and reduction occur in the tissues, but that the amount of each is not 